\title{
The Analysis of Human Papillomavirus Type 16 E6/E7 Genetic Variability in Jingjiang, Jiangsu Province, China
}

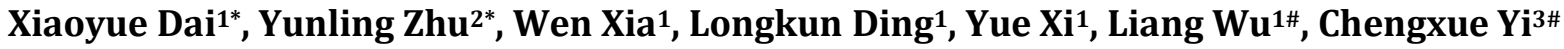 \\ ${ }^{1}$ School of Medicine, Jiangsu University, Affiliated Hospital of Jiangsu University, Zhenjiang, China \\ ${ }^{2}$ Department of Medical Laboratory, Jingjiang People's Hospital, Jingjiang, China \\ ${ }^{3}$ Zhenjiang Key Laboratory of Functional Chemistry, Zhenjiang College, Zhenjiang, China \\ Email: "wl_ujs@163.com, "yi.chengxue@163.com
}

How to cite this paper: Dai, X.Y., Zhu, Y.L., Xia, W., Ding, L.K., Xi, Y., Wu, L. and Yi, C.X. (2020) The Analysis of Human Papillomavirus Type 16 E6/E7 Genetic Variability in Jingjiang, Jiangsu Province, China. Journal of Biosciences and Medicines, $\mathbf{8}$, 89-103.

https://doi.org/10.4236/jbm.2020.83009

Received: February 3, 2020

Accepted: March 3, 2020

Published: March 6, 2020

Copyright $\odot 2020$ by author(s) and Scientific Research Publishing Inc. This work is licensed under the Creative Commons Attribution International License (CC BY 4.0).

http://creativecommons.org/licenses/by/4.0/ (c) (i) Open Access

\begin{abstract}
Human papillomavirus 16 (HPV-16) is a major high-risk type causing cervical cancer. The E6 and E7 genes in HPV-16 are the major virulent genes in HPV, and we wanted to investigate the polymorphism of E6 and E7 genes of HPV-16 originated from Jingjiang, Jiangsu province. In research, HPV-16 sample was collected, and the E6 and E7 genes fragments were amplified by PCR assay. The sequences of E6 and E7 genes were used for phylogenetic analysis by Mega 5.0 software. By comparison, the major mutations of E6 gene were T178G (41.67\%) and G658A (17\%), as well as C58G, T61A and G188C (14\%), T61C and C656A (11\%). The mutation of E7 gene was mainly C491A and T935A (23\%); G514C, G937C and G519C (11\%). The 68 nucleotide site deficiency (69.4\%) of E6 and 535 nucleotide site deficiency (23\%) of E7 were dominant. In our study, we did not find the relevance between the E6 and E7 genes mutations and pathologic severity. But we think the E6 and E7 genes mutation of HPV-16 might affect vaccine prevention and treatment effect.
\end{abstract}

\section{Keywords}

Human Papillomavirus, E6, E7, Gene Mutation, Phylogenetic Analysis

\section{Introduction}

Cervical carcinoma is one of the most common malignant tumors in the female, and $99.7 \%$ of cervical carcinoma patients were are detected with human papillomavirus (HPV) [1] [2]. HPV is considered to be the major causing for cervical ${ }^{*}$ Contributed equally to this work. 
cancer. Currently, more than 100 types of HPV have been found through the genomic sequencing. We found at least 30 types of HPV infection were related to cervical carcinoma. In the world, the HPV infection rate and its type distribution had dramatical difference in different countries or regions. The genome of HPV is double-stranded circular DNA, containing three functional zones including E1, E2, E4, E5, E6 and E7 proteins, participating in the function of duplicating, transcribing, translating, regulating and transforming [3]. According to carcinogenic risk, HPV can be divided into two categories, including low risk virus (HPV-6/11/40/42/43/44/61/72), which can cause low-grade cervical epithelial lesions and genital warts, and high risk virus

(HPV-16/18/31/33/35/39/45/51/52/58), its continuous infection is the direct cause of cervical cancer [4]. The most commonly detected hr HPV types in cervical specimens in Jiangsu were HPV-52 and HPV-16. And HPV-16 associated with high-grade squamous intraepithelial lesions. In the region of Suzhou, the most common hr HPV subtype in the spectrum of cervical diseases is HPV-16 [5]. HPV-16, HPV52, HPV58 are the most common hr HPV subtype in Wuxi [6]. HPV-16 is high risk virus, and the E6 and E7 oncoproteins are the most important virulence factors, which are responsible for cell transformation. The E6 protein involves in the degradation and inactivation of p53 [7]. E6 combines E6AP to form a complex, which leading the p53 protein to proteasome degradation, as well as the loss of cell cycle. E7 associates with a tumor suppressor protein (pRB) to make the cells immortal. E7 protein binds to the $\mathrm{pRb}-\mathrm{E} 2 \mathrm{~F}$ complex, resulting in its dissociation and the consequent release of E2F transcription factor. When the squamous cell is infected with the high-risk HPV, such as HPV 16 , the virus will integrate into the host gene and cause the sustained expression of E6/E7 in the cells [4]. Additionally, existing research results show that sequence mutations of E6 and E7 in HPV-16 have regional difference, such as different sub-types African type 1, African type 2, East-Asian type and so on. The presence of different mutations may reduce the effect of the vaccine, as well as may cause different degrees of cervical epithelial cell lesions. However, regional studies on mutations are still lacking in Jingjiang. In our study, HPV-16 samples were collected from Jingjiang people's hospital, and E6 and E7 oncogene sequencing were analysis to find the variation of E6 and E7 genes in this region and the distribution and affinity relationship of HPV-16 mutant strains. Our research could provide relevant epidemiological data for the prevention of HPV and the study of cervical cancer vaccine suitable for Chinese population.

\section{Materials and Methods}

\subsection{Sample Collection}

The study designed as a hospital-based cros-sectional research. Jingjiang is a city with small migrant population, which tends to be regionalized and aging. The study was conducted at the Jingjiang People's Hospital, and the specimens here also consist of those from the township areas. Under the principle of informed 
agreement, randomly selected 400 patients with cervical lesions from the Jingjiang first people's hospital from January 2019 to September 2019. The selection conditions were: 1) no history of hysterectomy and cervical surgery; 2) Married women who are not pregnant; 3) No vaginal medication within 2 days; 4) Clinical symptoms, such as abnormal vaginal bleeding, increased vaginal discharge, or cervical erosion. Patients ranged in age from 22 to 60 years. The procedure followed in this study complies with the ethical standards formulated by the Human Test Committee of our hospital, and is approved by the committee to obtain the informed consent of the patients and sign the informed consent of clinical research. Outpatient physicians use special specimen brushes to rotate at the junction of cervical squamous cells to obtain exfoliated epithelial cells, and then store them in fixative solution and send them for inspection as soon as possible.

\subsection{HPV-16 Diagnosis}

Using the German Eppendorf company's PCR instrument, human papillomavirus nucleic acid amplification typing test kit and DNA extraction reagent, the operation is performed strictly according to the actual and instructions of HPV Genotyping Diagnosis Kit (Gene chip technology, GangLong Biology, China). In vitro amplification, DNA reverse dot hybridization, enzyme-labeled color development, and results analysis. A total of 23 HPV genotypes (including 18 high-risk genotypes and 5 low-risk genotypes) were amplified and hybridized with typing probes to determine the presence of such subtypes of HPV-16 infection.

\subsection{E6 and E7 Gene Analysis}

The E6 and E7 sequences were obtained from HPV NC001526 strain. The sequences of E6 and E7 gene primers were listed in Table 1. The PCR reaction mixture $(25 \mu \mathrm{L})$ contained 50 pmol of each primer, $1 \mu \mathrm{L}$ template genomic DNA ( $<100 \mathrm{ng}$ ), $12.5 \mu \mathrm{L}$ master PCR mix (Vazyme Biotech Co., Ltd., Nanjing, China). The PCR amplification was performed in an automated thermal cycler (ABI 9700, Applied Biosystems, USA) with an initial denaturation $\left(94^{\circ} \mathrm{C}, 1 \mathrm{~min}\right)$ followed by 30 cycles of denatureation $\left(94^{\circ} \mathrm{C}, 10 \mathrm{sec}\right)$, annealing $\left(55^{\circ} \mathrm{C}, 30 \mathrm{sec}\right)$, and extension $\left(72^{\circ} \mathrm{C}, 30 \mathrm{sec}\right)$, with a single final extension $\left(72^{\circ} \mathrm{C}, 10 \mathrm{~min}\right)$. After amplification, $5 \mu \mathrm{L}$ of each PCR products were subjected to electrophresis on $1 \%$

Table 1. The primers for HPV-16 E6 and E7 genes.

\begin{tabular}{ccc}
\hline Primer & \multicolumn{1}{c}{ Sequence $\left(5^{\prime}-3^{\prime}\right)$} & PCR product $(\mathrm{bp})$ \\
\hline E6-F & AACTAAGGGCGTAACCGAAATC & 657 \\
E6-R & CTCCTCCTCTGAGCTGTCATTT & \\
E7-F & ACAGCAATACAACAAACCGTTG & 496 \\
E7-R & CATTACATCCCGTACCCTCTTC & \\
\hline
\end{tabular}


agarose gel. The positive PCR products were sequenced (Synbio Technologies company, Suzhou, China) and the E6 and E7 genes were analyzed.

\subsection{HPV-16 E6 and E7 Phylogenetic Analysis}

All HPV-16 E6 and E7 genes were analyzed by Mega5.0 software to complete phylogenetic trees via the $\mathrm{NJ}$ method. The reference sequences and login Numbers of the HPV-16 E6 and E7 genes used in this study are as follows: Asian-American type (AF402678), Amazonian (HM057182), African type 1 (AF472508), African type 2 (AF472509), East Asian type (AF534061), LZcc11-16 (EU918764), Human papillomavirus type 16 (FJ006723), CU7 (FJ610152), European German 131 type (AF536179).

\subsection{Clinicopathologic Classification of Sample}

Considering clinical diagnoses such as nodule size, cell morphology, presence of malignant cells, chronic cervical inflammation, glandular phosphating and so on, samples were ranked in four grades according to cervical intraepithelial neoplasia (CIN), which is an intraepithelial proliferative process with different degrees of severity depending on both the extension of the proliferation in the epithelium and the appearance of cellular atypia [8]. The samples of grade 1 present the same clinical characteristic that epithelial cells can be seen without epithelial lesions or malignant cells, additionally, grade 2 almost has inflammatory, cystic or fibroid. The trait of grade 3 mostly is chronic cervicitis and glandular epithelialization and grade 4 is confirmed squamous-cell carcinoma. This clinicopathologic classification aims to investigate the significance of the type and mutation in HPV according to pathological conditions.

\section{Results}

\subsection{The Detection of HPV-16}

When using HPV genotyping diagnosis kit, different sites represented different HPV types. Figure 1 is one positive result in specimen.

\subsection{HPV-16 E6 and E7 Genes Amplification}

Both E6 and E7 genes had a good amplification in our experiment, and the length of both $\mathrm{E} 6$ and $\mathrm{E} 7$ products were consistent with predictions, as depicted in Figure 2, Figure 3.

\subsection{The Mutation Analysis of E6 Gene}

All the positive samples of E6 and E7 genes were amplified and sequenced for at least twice to avoid PCR mismatch errors, then the sequences were analyzed by BLAST alignment.

All E6 nucleotide mutation sites of HPV-16 positive samples were compared with GenBank stain (KY994539.1). In Table 2, there are 27 mutation sites while having 32 kinds of mutation affairs, including one site with more than two 


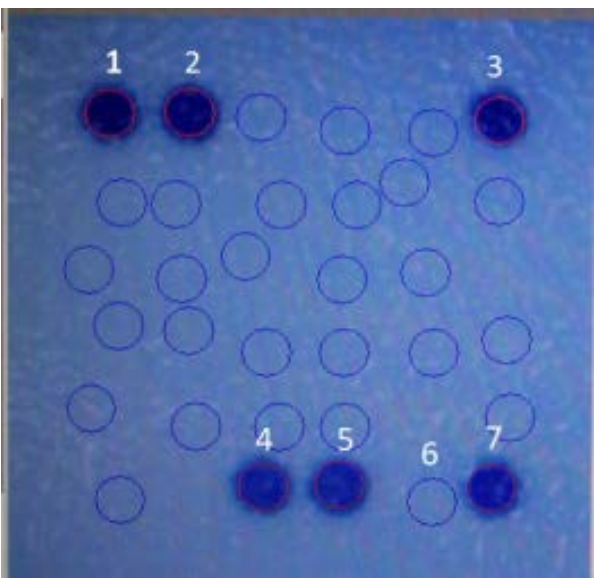

Figure 1. The results of genotyping diagnosis. The sites 1,3 and 7 were positive reference, and the site 6 was negative reference, and the sites 4 and 5 were internal inference indexes of specimen, and the site 2 was diagnosis of HPV- 16.

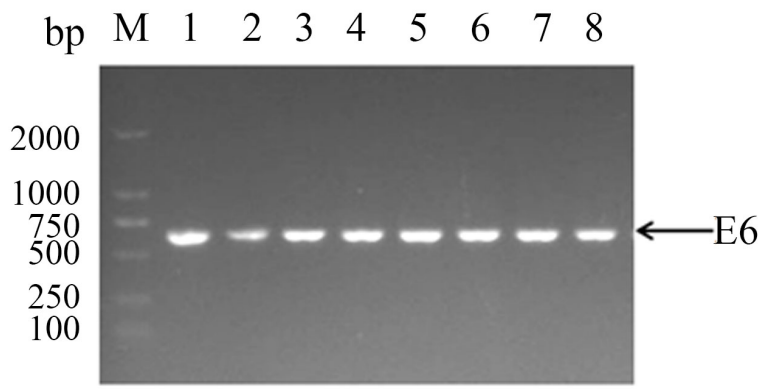

Figure 2. Polymerase chain reaction results of E6 gene (only partial bands are listed). M, DNA Marker; $1-8$, PCR gene amplification results of positive samples after genotyping diagnosis selection.

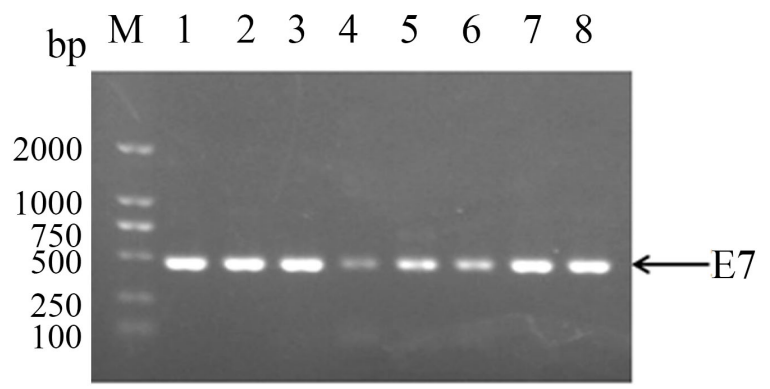

Figure 3. Polymerase chain reaction results of E7 gene (only partial bands are listed). $M$, DNA Marker; 1 - 8, PCR gene amplification results of positive samples after genotyping diagnosis selection.

Table 2. The specific mutation conditions of HPV-16 E6 nucleotide mutation site (only variable site listed).

\begin{tabular}{ccccc}
\hline Base Sites & Prototype & Mutation & Sample Size & Mutation Rate (\%) \\
\hline 58 & C & G & 5 & 13.89 \\
61 & T & A & 5 & 13.89 \\
61 & T & C & 4 & 11.11 \\
\hline
\end{tabular}




\section{Continued}

\begin{tabular}{|c|c|c|c|c|}
\hline 78 & $\mathrm{~T}$ & G & 1 & 2.78 \\
\hline 89 & $\mathrm{C}$ & $\mathrm{T}$ & 2 & 5.56 \\
\hline 94 & G & A & 3 & 8.33 \\
\hline 94 & $\mathrm{G}$ & $\mathrm{T}$ & 1 & 2.78 \\
\hline 95 & $\mathrm{G}$ & $\mathrm{T}$ & 2 & 5.56 \\
\hline 139 & A & G & 2 & 5.56 \\
\hline 142 & A & G & 1 & 2.78 \\
\hline 162 & $\mathrm{~A}$ & $\mathrm{~T}$ & 2 & 5.56 \\
\hline 178 & $\mathrm{~T}$ & $\mathrm{~A}$ & 3 & 8.33 \\
\hline 178 & $\mathrm{~T}$ & G & 15 & 41.67 \\
\hline 183 & $\mathrm{~T}$ & $\mathrm{C}$ & 1 & 2.78 \\
\hline 185 & $\mathrm{~T}$ & $\mathrm{G}$ & 2 & 5.56 \\
\hline 188 & $\mathrm{G}$ & $\mathrm{A}$ & 1 & 2.78 \\
\hline 188 & G & $\mathrm{C}$ & 5 & 13.89 \\
\hline 191 & $\mathrm{~T}$ & $\mathrm{~A}$ & 1 & 2.78 \\
\hline 228 & $\mathrm{~T}$ & A & 1 & 2.78 \\
\hline 241 & $\mathrm{~T}$ & G & 1 & 2.78 \\
\hline 260 & G & $\mathrm{T}$ & 2 & 5.56 \\
\hline 267 & G & $\mathrm{T}$ & 1 & 2.78 \\
\hline 267 & G & A & 1 & 2.78 \\
\hline 348 & G & A & 1 & 2.78 \\
\hline 442 & A & $\mathrm{C}$ & 3 & 8.33 \\
\hline 655 & $\mathrm{~T}$ & $\mathrm{C}$ & 1 & 2.78 \\
\hline 656 & $\mathrm{C}$ & G & 1 & 2.78 \\
\hline 656 & $\mathrm{C}$ & $\mathrm{A}$ & 4 & 11.11 \\
\hline 657 & A & G & 2 & 5.56 \\
\hline 658 & G & $\mathrm{A}$ & 6 & 16.67 \\
\hline 660 & G & $\mathrm{A}$ & 2 & 5.56 \\
\hline 662 & A & G & 1 & 2.78 \\
\hline 665 & A & G & 1 & 2.78 \\
\hline
\end{tabular}

mutations. Compared with HN-LU-SCC-26 standard strain (KY994539.1), 15 samples (41.67\%) E6 gene occur T178G mutation. This nucleotide mutation caused amino acid change with Asp to Glu converting. This mutation site also has three times of T178A variations, resulting in the amino acid change of D25E [9]. Other main nucleotide mutations included G658A (17\%), C58G (14\%), T61A (14\%), G188C (14\%), T61C (11\%) and C656A (11\%).

The E6 gene nucleotide deficiency in our HPV-16 positive samples had a high frequency. We found the 68 nucleotide site had a high frequency gene deletion, shown in Table 3, and 25 of total 36 samples had the gene deletion. It means the nucleotide site deficiency rate was $69.4 \%$. 
Table 3. The specific deficiency sites of HPV-16 E6 nucleotide mutation site (only variable site listed).

\begin{tabular}{|c|c|c|c|c|c|c|c|c|}
\hline & \multicolumn{8}{|c|}{ Base Sites } \\
\hline & 57 & 61 & 67 & 68 & 69 & 654 & 662 & 669 \\
\hline prototype & $\mathrm{C}$ & $\mathrm{T}$ & $\mathrm{T}$ & A & A & C & A & $\mathrm{T}$ \\
\hline JJ01 & & & & $\mathrm{D}$ & & & & \\
\hline JJ02 & & & & $\mathrm{D}$ & & & & \\
\hline $\mathrm{JJ} 03$ & & & & $\mathrm{D}$ & & & & \\
\hline JJ04 & & & & $\mathrm{D}$ & & & & \\
\hline $\mathrm{JJ} 05$ & & & & $\mathrm{D}$ & & & & \\
\hline \multicolumn{9}{|l|}{ JJ06 } \\
\hline JJ07 & & & & $\mathrm{D}$ & $\mathrm{D}$ & & & \\
\hline JJ08 & & & & $\mathrm{D}$ & $\mathrm{D}$ & $\mathrm{D}$ & & \\
\hline JJ09 & $\mathrm{D}$ & & & $\mathrm{D}$ & & & & \\
\hline $\mathrm{JJ} 10$ & & $\mathrm{D}$ & & $\mathrm{D}$ & $\mathrm{D}$ & & $\mathrm{D}$ & \\
\hline JJ11 & & & & $\mathrm{D}$ & & & & $\mathrm{D}$ \\
\hline JJ12 & & & & $\mathrm{D}$ & & & & \\
\hline $\mathrm{JJ} 13$ & & & $\mathrm{D}$ & & & & & \\
\hline JJ14 & & & & $\mathrm{D}$ & & & & \\
\hline $\mathrm{JJ} 15$ & & & & $\mathrm{D}$ & & & & \\
\hline JJ16 & & & & $\mathrm{D}$ & & & & \\
\hline $\mathrm{JJ} 17$ & & & & $\mathrm{D}$ & & & & \\
\hline \multicolumn{9}{|l|}{$\mathrm{JJ} 18$} \\
\hline \multicolumn{9}{|l|}{ JJ19 } \\
\hline $\mathrm{JJ} 20$ & & & & $\mathrm{D}$ & & & & \\
\hline $\mathrm{JJ} 21$ & & & & $\mathrm{D}$ & & & & \\
\hline $\mathrm{JJ} 22$ & & & & $\mathrm{D}$ & & & & \\
\hline $\mathrm{JJ} 23$ & & & & $\mathrm{D}$ & & & & \\
\hline $\mathrm{JJ} 24$ & & & & $\mathrm{D}$ & & & & \\
\hline \multicolumn{9}{|l|}{$\mathrm{JJ} 25$} \\
\hline \multicolumn{9}{|l|}{ JJ26 } \\
\hline \multicolumn{9}{|l|}{ JJ27 } \\
\hline $\mathrm{JJ} 28$ & & & & $\mathrm{D}$ & & & & \\
\hline \multicolumn{9}{|l|}{ JJ29 } \\
\hline \multicolumn{9}{|l|}{ JJ30 } \\
\hline \multicolumn{9}{|l|}{ JJ31 } \\
\hline $\mathrm{JJ} 32$ & & & & $\mathrm{D}$ & $\mathrm{D}$ & & & \\
\hline $\mathrm{JJ} 33$ & & & & $\mathrm{D}$ & & & & \\
\hline $\mathrm{JJ} 34$ & & & & $\mathrm{D}$ & & & & \\
\hline $\mathrm{JJ} 35$ & & & & $\mathrm{D}$ & & & & \\
\hline $\mathrm{JJ} 36$ & & & & & & & & \\
\hline
\end{tabular}

D: deficiency; JJ01-36: sample numbers. 


\subsection{The Mutation Analysis of E7 Gene}

The nucleotide mutation sites with HPV-16 E7 gene were listed in Table 4. There are 25 mutation sites while having 30 kinds of mutations. Compared with HN-LU-SCC-26 standard strain, the main nucleotide mutations were C491A (23\%), T935A (23\%), G514C (11\%), G937C (11\%), G519C (11\%). Additionally, the $\mathrm{A} 646 \mathrm{C}$ variation accounting for $9 \%$, resulting in the amino acid change of $\mathrm{N} 29 \mathrm{H}$ [10]. The G666A nucleotide mutation accounts for 6\%, which was the same sense mutation. Furthermore, in Table 5, E7 gene in our sample also had

Table 4. The specific mutation conditions of HPV-16 E7 nucleotide mutation site (only variable site listed).

\begin{tabular}{|c|c|c|c|c|}
\hline Base Sites & Prototype & Mutation & Sample Size & Mutation Rate (\%) \\
\hline 487 & $\mathrm{~T}$ & A & 2 & 5.71 \\
\hline 491 & $\mathrm{C}$ & A & 8 & 22.86 \\
\hline 511 & $\mathrm{~T}$ & G & 1 & 2.86 \\
\hline 514 & G & $\mathrm{C}$ & 4 & 11.43 \\
\hline 517 & $\mathrm{~T}$ & A & 2 & 5.71 \\
\hline 517 & $\mathrm{~T}$ & G & 1 & 2.86 \\
\hline 519 & G & $\mathrm{C}$ & 4 & 11.43 \\
\hline 519 & G & A & 1 & 2.86 \\
\hline 520 & $\mathrm{~T}$ & A & 2 & 5.71 \\
\hline 525 & G & C & 1 & 2.86 \\
\hline 533 & A & $\mathrm{T}$ & 1 & 2.86 \\
\hline 613 & G & A & 1 & 2.86 \\
\hline 646 & A & $\mathrm{C}$ & 3 & 8.57 \\
\hline 658 & G & A & 2 & 5.71 \\
\hline 666 & G & A & 2 & 5.71 \\
\hline 666 & G & $\mathrm{T}$ & 3 & 8.57 \\
\hline 676 & G & A & 3 & 8.57 \\
\hline 758 & G & $\mathrm{C}$ & 1 & 2.86 \\
\hline 843 & $\mathrm{~T}$ & C & 2 & 5.71 \\
\hline 849 & G & A & 2 & 5.71 \\
\hline 892 & C & $\mathrm{T}$ & 2 & 5.71 \\
\hline 895 & G & A & 1 & 2.86 \\
\hline 903 & C & G & 1 & 2.86 \\
\hline 928 & G & A & 1 & 2.86 \\
\hline 935 & $\mathrm{~T}$ & A & 8 & 22.86 \\
\hline 937 & G & C & 4 & 11.43 \\
\hline 937 & G & $\mathrm{T}$ & 2 & 5.71 \\
\hline 937 & G & A & 1 & 2.86 \\
\hline 938 & $\mathrm{~T}$ & G & 2 & 5.71 \\
\hline 939 & G & $\mathrm{T}$ & 2 & 5.71 \\
\hline 939 & G & A & 1 & 2.86 \\
\hline
\end{tabular}


Table 5. The specific deficiency sites of HPV-16 E7 nucleotide mutation site (only variable site listed).

\begin{tabular}{|c|c|c|c|c|c|c|c|c|c|c|c|c|c|c|}
\hline & \multicolumn{14}{|c|}{ Base Sites } \\
\hline & 517 & 520 & 515 & 523 & 524 & 529 & 532 & 535 & 538 & 546 & 889 & 892 & 897 & 907 \\
\hline prototype & $\mathrm{T}$ & $\mathrm{T}$ & $\mathrm{C}$ & $\mathrm{C}$ & A & A & A & A & A & A & $\mathrm{C}$ & $\mathrm{C}$ & $\mathrm{C}$ & A \\
\hline $\mathrm{JJ} 01$ & & & & & & & & $\mathrm{D}$ & & & & & & \\
\hline $\mathrm{JJ} 02$ & & & & $\mathrm{D}$ & & & & $\mathrm{D}$ & & & & & & \\
\hline $\mathrm{JJ} 03$ & & & & & & $\mathrm{D}$ & & & & $\mathrm{D}$ & & & & \\
\hline $\mathrm{JJ} 04$ & & & & $\mathrm{D}$ & & & & & & & & & & \\
\hline JJ05 & & & & & & & & & & & & & & \\
\hline JJ06 & $\mathrm{D}$ & & & & & & & $\mathrm{D}$ & & & & & & \\
\hline JJ07 & & & & & & & & & & & & & & \\
\hline $\mathrm{JJ} 08$ & & & & & $\mathrm{D}$ & & & $\mathrm{D}$ & & & & & & \\
\hline JJ09 & & & & & $\mathrm{D}$ & D & $\mathrm{D}$ & & $\mathrm{D}$ & & & & & \\
\hline $\mathrm{JJ} 10$ & & & & & & & & D & & & & & & \\
\hline JJ11 & & & & & & & & & & & & & & \\
\hline $\mathrm{JJ} 12$ & & & & $\mathrm{D}$ & & & & & & & & & & \\
\hline $\mathrm{JJ} 13$ & D & & & & & & & & & & & & & \\
\hline JJ14 & & & & & & & & & & & & & & \\
\hline $\mathrm{JJ} 15$ & & $\mathrm{D}$ & D & & & & & $\mathrm{D}$ & & & & & & \\
\hline JJ16 & & & & & & & & & & & & & & \\
\hline JJ17 & & & $\mathrm{D}$ & & & & & & & & & & & \\
\hline $\mathrm{JJ} 18$ & & & & & & & & $\mathrm{D}$ & & & & & & \\
\hline JJ19 & & & & & & & & D & & & & & & \\
\hline JJ20 & & & & & $\mathrm{D}$ & & D & & & & & & & \\
\hline $\mathrm{JJ} 21$ & & & & & & & & & & & & & & \\
\hline $\mathrm{JJ} 22$ & & & & & & & & & & & & $\mathrm{D}$ & $\mathrm{D}$ & \\
\hline $\mathrm{JJ} 23$ & & & & & & & & & & & $\mathrm{D}$ & & & \\
\hline $\mathrm{JJ} 24$ & & & & & & & & & & & $\mathrm{D}$ & & & \\
\hline $\mathrm{JJ} 25$ & & & & & & & & & & & & & & \\
\hline JJ26 & & & & & & & & & & & & & & $\mathrm{D}$ \\
\hline $\mathrm{JJ} 27$ & & & & & & & & & & & & & & \\
\hline $\mathrm{JJ} 28$ & & & & & & & & & & & & & & \\
\hline JJ29 & & & & & & & & & & & $\mathrm{D}$ & & & $\mathrm{D}$ \\
\hline $\mathrm{JJ} 30$ & & & & & & & & & & & & & & \\
\hline $\mathrm{JJ} 31$ & & & & & & & & & & & & & & \\
\hline $\mathrm{JJ} 32$ & & & & & & & & & & & & & & \\
\hline $\mathrm{JJ} 33$ & & & & & & & & & & & & $\mathrm{D}$ & & \\
\hline $\mathrm{JJ} 34$ & & & & & & & & & & & & & & \\
\hline $\mathrm{JJ} 35$ & & & & & & & & & & & & D & & \\
\hline
\end{tabular}

D: deficiency; JJ01-35: sample numbers. 
nucleotide deficiency. The 535 nucleotide site distinctly occurs gene deletion, 8 of 35 samples come to this, indicating the rate of 535 nucleotide site deficiency was $23 \%$.

\subsection{HPV-16 E6 and E7 Nucleotide Phylogenetic Analysis}

According to Neighbor-joining method in Mega 5.1 software, all the samples HPV-16 E6 genes sequences and other reference HPV-16 types E6 sequences were analyzed to build phylogenetic trees. It can be seen from the phylogenetic tree diagram, in Figure 4, that the European variation is closely related to the Asian variation, and 6 samples associate with all inference variation stain in the same branch. The others are divided into two branches, which means different regions play an important role in the variation of gene in this analysis.

According to Neighbor-joining method in Mega5.1 software, 35 specimen of HPV-16 E7 genes and foreign HPV-16 types in other countries were analyzed to build phylogenetic trees. It can be seen from the phylogenetic tree diagram that the tree can be distinctly grouped into three branches, in Figure 5, and 11 samples weakly associate with all inference variation stain in the same branch. The remains are divided into two branches, which means different regions play an important role in the variation of gene in this analysis as well.

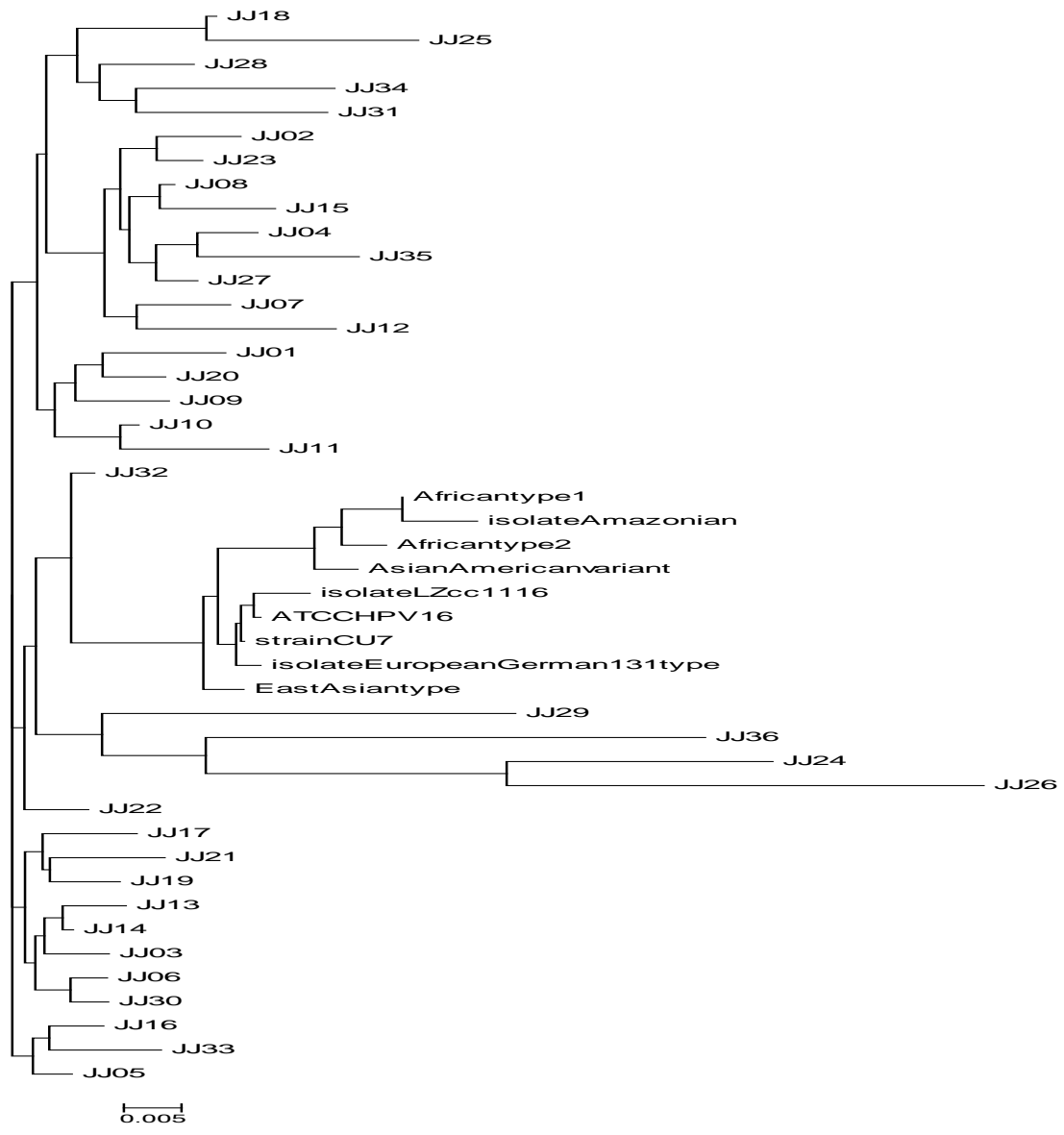

Figure 4. Phylogenetic tree constructed from fragment of E6 variants. 


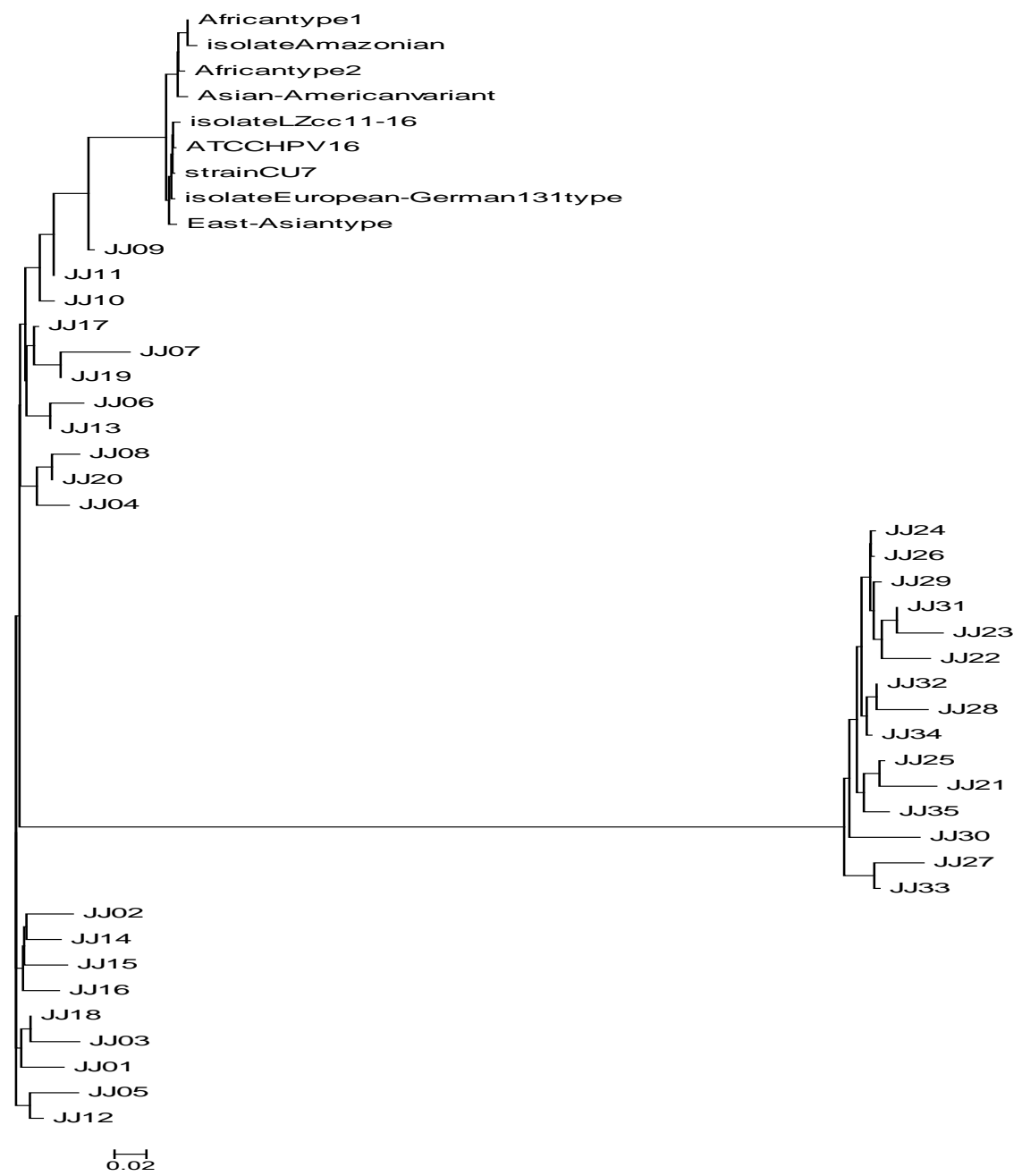

Figure 5. Phylogenetic tree constructed from fragment of E7 variants.

\subsection{Clinicopathologic Correlation}

Collected samples were divided into 4 grades in according to pathological conditions ranging from light to heavy, statistics are shown in Figure 6, Figure 7. Figure 6 is the major mutations of E6 gene, and Figure 7 is the major mutations of E7 gene.

It's showed that major mutations may not be relevant to pathologic severity, both E6 and E7 gene. However, in Figure 6, these mutations are presented in specimens with severe pathology.

\section{Discussion}

The method of gene chip was widely used in our country for HPV infection diagnosis because of its sensitive and peculiar. To some extent, its excellent characteristic originates from sequencing by hybridization. When making the target genes marked with fluorescence, the known nucleotide array on gene chip identifies target gene and connects with it in specificity. Kares [11] considered that this kind of genetic typing in the affirm of HPV subtype is preferably adoptable. 


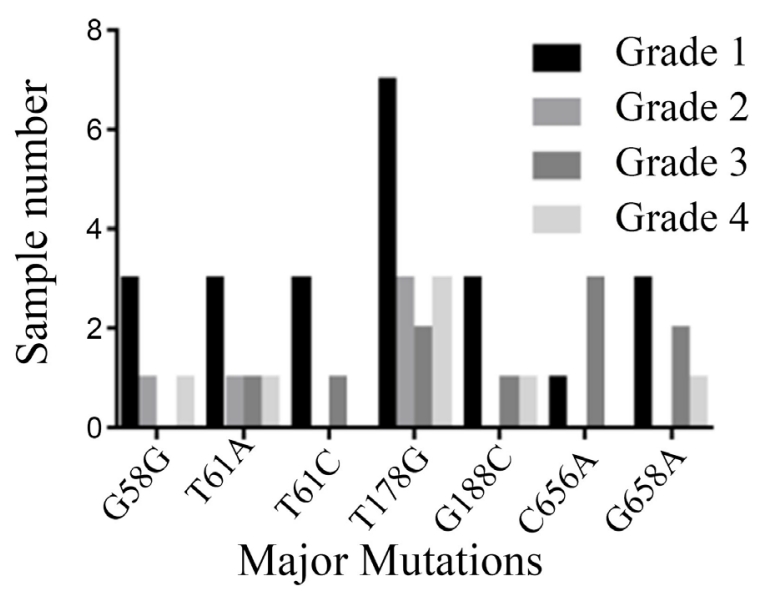

Figure 6. The relationship between major mutations of E6 gene with pathologic severity conditions.

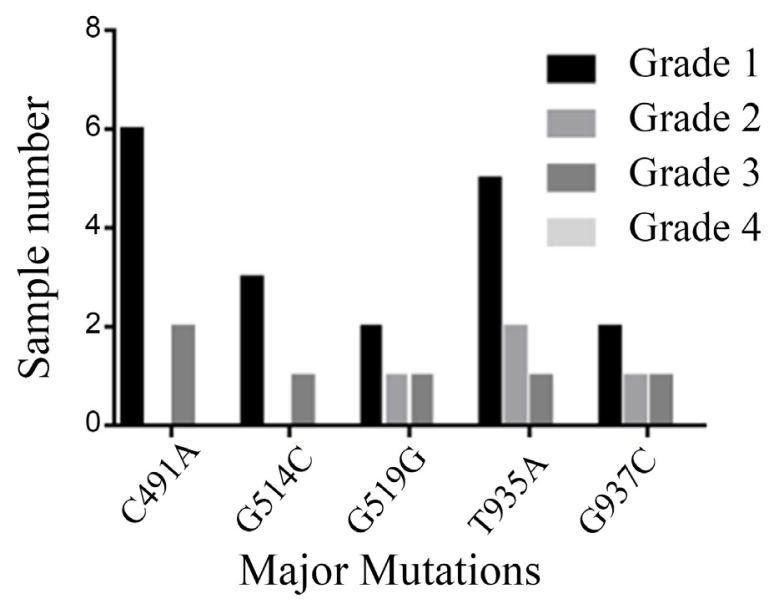

Figure 7. The relationship between major mutations of E7 gene with pathologic severity conditions.

In our study, we collected the HPV-16 type samples and the E6 and E7 genes [6] sequences were studied. For E6 gene, the mutation of E6 gene can lead to inactivation of P53, a tumor suppressor gene, suppress the tumor inhibition pathway of p53-Notch1 and resulting in the insufficient differentiation and abnormal growth of cells [7]. That will lead to the occurrence of cancer [12]. At the same time, HPV-16 E6 protein could induce hTERT expression by transcriptional function, thereby providing a mechanistic explanation for E6-mediated increases in telomerase activity [13]. The E7 virulence protein can bind $\mathrm{pRb}$ and inactivate it, that will cause the degradation of tumor suppressor $\mathrm{pRb}$. Due to the sustained expression of HPV E6 and E7, that is why the person who infected with HPV 16 has a high cervical cancer incidence. Hence, the HPV early-protein E6 and E7 were used for HPV therapeutic vaccine [11]. But there were a large number of reports that the HPV E6 and E7 gene and protein have high frequency mutation in global. The mutates for E6 and E7 seem directly to affect the effect of vaccine treatment. HPV 16 is the most important subtype related to cervical 
cancer, and it had an important clinical significance to known the mutant of E6 and E7 genes in Jingjiang, Jiangsu province. The results are benefit to the HPV infection and cervical cancer precision and individualized treatment.

Our results indicated that the most common mutation site of HPV-16 E6 gene in Jingjiang was 178 nucleotide, changing from $T$ to $G$ and substituting Asp with Glu. Another common mutation type was the replacement of $\mathrm{T}$ to $\mathrm{A}$, this induces the variation of D25E [9], which was similar to HPV 16 strain originated from Guangdong province. In HPV 16 strain originated from Yunnan province [14], 178 nucleotide mutation frequency gets up to 50\%, which was slightly higher than that in Jingjiang originated strains. The mutation alike can be shown in the research of Qingdao [15], Shandong region [16] [17], with the simple difference of mutation frequency. Other mutations including G658A, C58G, T61A, G188C, T61C and C656A were also commonly found in many kinds of HPV-16 strains, and mutant rate was different in HPV-16 strains originated from different regions. In HPV-16 E7 gene originated Jingjiang, the two prevalent mutation sites were 491 and 935 nucleotide, changing from $\mathrm{C}$ to $\mathrm{A}$ and $\mathrm{T}$ to $\mathrm{A}$. There mutant sites were different from other strains such as Yunnan strain and Xinjiang strain. In Yunnan strain [18] and Xinjiang strain [19], the most high frequency mutant site was the 647 nucleotide variates from A to G. In our research, we also found some nucleotide deficiency in HPV 16 E6 and E7 genes. The most high-frequency deficiency was in E6-68 nucleotide site, accounting for the proportion of $69.4 \%$, as well as in E7-535 nucleotide site, accounting for the proportion of $23 \%$.

The results of the analysis of nucleotide phylogenetic trees indicated that the E6 and E7 gene in HPV 16 originated from Jingjiang can be divided into three relatively independent groups. We think this phenomenon might be related to the situation that people in Jingjiang were less contact with the people in other cities and less external population. People married with each other just among the urbans or country folks so as to result in the separation of gene factor.

The variation of two oncogenes, including E6 and E7 of HPV 16 might affect the carcinogenicity to host. In the past study, researchers found many mutation sites related to the virus virulence changes [20]. In our further study, we should continue to study the relationship between oncogenes variation the virus virulence. Due to the results of mutation, we guess that it means a lot if some mutations are associated with cell situation of cervical cancer and occur more frequently in cervical patients than in precancerous lesions, which may hint some mutations need to attach more importance. Nevertheless, when we observe the cell situation of the cervical smear and cervical tissue from samples which are detected for HPV-16, the relation of pathologic severity and mutation seems to be inexisted. Of course, this result probably exists individual errors that identify the pathological situation. To some extent, this may be useful for other studies and deserve further researches.

\section{Conclusion}

HPV-16 is a major high-risk type causing cervical cancer, and previous studies 
have shown that its sequence mutation presents regional differences. Therefore, the study on E6 and E7 variation of HPV-16 in different regions is an important part of cervical cancer epidemiology, and can also be employed to study the carcinogenic accumulation data of E6 and E7. The mutate result of Jingjiang samples is a little distinct from other regions so that area characteristic can be taken into account. Nucleotide phylogenetic trees indicated that the E6 and E7 gene in HPV 16 originated from Jingjiang can be divided into relatively independent groups, which means different regions play an important role in the variation of gene and genetic testing is essential in every region. Clinical analysis results indicate that major mutations of both E6 and E7 gene may not be relevant to pathologic severity, but we need to enlarge the sample size and do further study.

\section{Conflicts of Interest}

The authors declare no conflicts of interest regarding the publication of this paper.

\section{References}

[1] Hu, Z. and Ma, D. (2018) The Precision Prevention and Therapy of HPV-Related Cervical Cancer: New Concepts and Clinical Implications. Cancer Medicine, 7, 5217-5236. https://doi.org/10.1002/cam4.1501

[2] Li, L., Zheng, Z. and Li, L. (2019) Evaluation of Human-Papillomavirus Screening for Cervical Cancer in China's Rural Population. PeerJ, 7, e8152.

https://doi.org/10.7717/peerj.8152

[3] Fan, Y., Meng, Y., Yang, S., Wang, L., Zhi, W., Lazare, C., Cao, C. and Wu, P. (2018) Screening of Cervical Cancer with Self-Collected Cervical Samples and Next-Generation Sequencing. Disease Markers, 482, 6547. https://doi.org/10.1155/2018/4826547

[4] Hoppe-Seyler, K., Bossler, F., Braun, J.A., Herrmann, A.L. and Hoppe-Seyler, F. (2018) The HPV E6/E7 Oncogenes: Key Factors for Viral Carcinogenesis and Therapeutic Targets. Trends in Microbiology, 26, 158-168. https://doi.org/10.1016/j.tim.2017.07.007

[5] Li, Z., Xie, L. and Zhang, S. (2011) Sub-Type Specific Distribution of HPV Cases with Cervical Diseases in Suzhou. Jiangsu Journal of Preventive Medicine, 22, 7-9. http://kns.cnki.net/kcms/detail/detail.aspx?FileName=JSYF201105002\&DbName=C $\underline{\mathrm{JFQ} 2011}$

[6] Chen, Y., Zhang, Y., Chen, M. and Zou, J. (2014) Status of HPV Infection among Population of Cervical Cancer Screening Pilot Program in Wuxi New District. Chinese Journal of Cancer Prevention and Treatment, 21, 985-988.

[7] Martinez-Zapien, D., Ruiz, F.X., Poirson, J., Mitschler, A., Ramirez, J., Forster, A., Cousido-Siah, A., Masson, M., Vande, P.S., Podjarny, A., Trave, G. and Zanier, K. (2016) Structure of the E6/E6AP/p53 Complex Required for HPV-Mediated Degradation of p53. Nature, 529, 541-545. https://doi.org/10.1038/nature16481

[8] Verheijen, R.H. and Helmerhorst, T.J. (2001) Addition of High-Risk HPV Testing Improves the Current Guidelines on Follow-Up after Treatment for Cervical Intraepithelial Neoplasia. British Journal of Cancer, 84, 796-801. https://xs.scihub.ltd https://doi.org/10.1054/bjoc.2000.1689

[9] Nobbenhuis, M.A., Meijer, C.J., van den Brule, A.J., Rozendaal, L., Voorhorst, F.J., 
Risse, E.K., Cai, H.B., Chen, C.C. and Ding, X.H. (2010) Human Papillomavirus Type 16 E6 Gene Variations in Chinese Population. European Journal of Surgical Oncology, 36, 160-163. https://doi.org/10.1016/j.ejso.2009.07.186

[10] Zhang, L., Yang, B., Zhang, A., Zhou, A., Yuan, J., Wang, Y., Sun, L., Cao, H., Wang, J. and Zheng, W. (2016) Association between Human Papillomavirus Type 16 E6 and E7 Variants with Subsequent Persistent Infection and Recurrence of Cervical High-Grade Squamous Intraepithelial Lesion after Conization. The Journal of Medical Virology, 88, 1982-1988. https://doi.org/10.1002/jmv.24541

[11] Kares, S., Veijalainen, O., Kholova, I., Tirkkonen, M., Vuento, R., Huhtala, H., Tuimala, V., Maenpaa, J. and Kujala, P. (2019) HIGH-RISK HPV Testing as the Primary Screening Method in an Organized Regional Screening Program for Cervical Cancer: The Value of HPV16 and HPV18 Genotyping? APMIS, 127, 710-716. https://doi.org/10.1111/apm.12990

[12] Travé, G. and Zanier, K. (2016) HPV-Mediated Inactivation of Tumor Suppressor p53. Cell Cycle, 15, 2231-2232. https://doi.org/10.1080/15384101.2016.1191257

[13] Liu, T., Yuan, X. and Xu, D. (2016) Cancer-Specific Telomerase Reverse Transcriptase (TERT) Promoter Mutations: Biological and Clinical Implications. Genes (Basel), 7, 38. https://doi.org/10.3390/genes7070038

[14] Yang, L., Yang, H., Wu, K., Shi, X., Ma, S. and Sun, Q. (2014) Prevalence of HPV and Variation of HPV 16/HPV 18 E6/E7 Genes in Cervical Cancer in Women in South West China. The Journal of Medical Virology, 86, 1926-1936. https://doi.org/10.1002/jmv.24043

[15] Bi, Q., Zhang, L., Zhao, Z., Mu, X., Zhang, M. and Wang, P. (2015) Human Papillomavirus Prevalence and Genotypes Distribution among Female Outpatients in Qingdao, East China. The Journal of Medical Virology, 87, 2114-2121. https://doi.org/10.1002/jmv.24281

[16] Yuan, X., Yang, Y., Gu, D., Liu, H., Yang, H. and Wang, M. (2011) Prevalence of Human Papillomavirus Infection among Women with and without Normal Cervical Histology in Shandong Province, China. Archives of Gynecology and Obstetrics, 283, 1385-1389. https://doi.org/10.1007/s00404-010-1584-0

[17] Xi, J., Chen, J., Xu, M., Yang, H., Luo, J., Pan, Y., Wang, X., Qiu, L., Yang, J. and Sun, Q. (2017) Genetic Variability and Functional Implication of the Long Control Region in HPV-16 Variants in Southwest China. PLoS ONE, 12, e182388. https://doi.org/10.1371/journal.pone.0182388

[18] Yang, L.J., Yue, Y.F., Chen, J.Y., Pan, Y., Zhao, Y.J., Ma, S.H. and Sun, Q.M. (2012) The Analysis of Human Papillomavirus Type 16 E6/E7 Genetic Variability in Yunnan Province, China. Chinese Journal of Virology, 28, 645-651.

https://www.altmetric.com/details/1237269

[19] Wang, L., Wang, P., Ren, Y., Du, J., Jiang, J., Jia, X., Chen, C. and Wang, Y. (2016) Prevalence of High-Risk Human Papillomavirus (HR-HPV) Genotypes and Multiple Infections in Cervical Abnormalities from Northern Xinjiang, China. PLoS ONE, 11, e0160698. https://doi.org/10.1371/journal.pone.0160698

[20] Sang, B.C. and Barbosa, M.S. (1992) Single Amino Acid Substitutions in "Low-Risk" Human Papillomavirus (HPV) Type 6 E7 Protein Enhance Features Characteristic of the "High-Risk" HPV E7 Oncoproteins. Proceedings of the National Academy of Sciences of the United States of America, 89, 8063-8067. https://doi.org/10.1073/pnas.89.17.8063 